\title{
Prensa y sociedad en Chile en los comienzos republicanos: El Araucano como modelo de prensa estatal ${ }^{1}$
}

\author{
Eduardo SANTA CRUZ \\ Universidad de Chile \\ esantacr@uchile.cl
}

Recibido: 23 de junio de 2013

Aceptado: 19 de noviembre de 2013

\section{Resumen}

El objetivo del texto es mostrar la particular experiencia del periódico El Araucano, en los inicios de la vida republicana chilena. En el marco de un naciente espacio público excluyente y exclusivo a la elite aristocrática que se disputaba el control y el sentido del nuevo orden y gracias al sello que le impuso Andrés Bello, El Araucano configura un cierto modelo de prensa de carácter estatal que, a partir de la naturalización del orden conservador triunfante en la guerra civil de 1830, se centra en la difusión de los fundamentos de la sociedad a construir y toma una relativa distancia de la lucha política cotidiana. De todas formas, es una expresión más de la prensa doctrinaria prevaleciente en las nuevas repúblicas durante la mayor parte del siglo XIX.

Palabras clave: Historia Prensa Latinoamericana, Historia Prensa Chilena, Modelos prensa, Prensa estatal.

\section{Journalism and society in Chile in the early Republican: El Araucano as state journalism model}

\begin{abstract}
The aim of the text is to show the particular experience of the newspaper El Araucano, at the beginning of the chilean republican life. In the framework of a nascent public space inclusive and exclusive to the aristocratic elite which was played to the control and direction of the new order and thanks to seal imposed by Andrés Bello, El Araucano configure some model of state journalism, from the naturalization of the triumphant conservative order in the civil war of 1830 focuses on the dissemination of the fundamentals of society to build and takes a relative distance from the daily political struggle. Anyway, is one more expression of the prevailing doctrinal press in the new republics during most of the 19th century. Keywords: Latin-American and Chilean journalism, Chilean press history, Journalism model, State journalism.
\end{abstract}

1 Proyecto Fondo Nacional de Ciencia y Tecnología No 1085029, Chile: Espacio público y subjetividad en América Latina: Bello, Darío y Martí. El presente texto se inscribe al interior de una investigación más amplia y de mayor alcance que se planteó examinar dos dispositivos culturales propios del siglo XIX en América Latina. En primer lugar, la dimensión proyectual o fundacional que caracteriza la obra de Andrés Bello y, en segundo lugar, las tensiones o desencuentros que, en relación con el mundo moderno, caracteriza obras como los trabajos periodísticos de José Martí, donde interesa ver el modo como la modernidad deja de ser primariamente "proyecto" para devenir sobre todo "experiencia". Forma parte constituyente de la descripción de estos dos emplazamientos su análisis en el interior de las transformaciones que vive la prensa en la época y cómo se articulan ellas con el desarrollo del espacio público. En esta investigación el autor de este artículo se desempeñó como co-investigador. 


\section{Referencia normalizada}

SANTA CRUZ, Eduardo (2014): "Prensa y sociedad en Chile en los comienzos republicanos: El Araucano como modelo de prensa". Estudios sobre el Mensaje Periodístico. Vol. 20, Núm. 1 (enero-junio), págs.: 557-566. Madrid, Servicio de Publicaciones de la Universidad Complutense.

Sumario: 1. Introducción. 2. Los orígenes del campo periodístico chileno. 3. Las características de $E l$ Araucano. 4. Conclusiones. 5. Referencias bibliográficas.

\section{Introducción}

Los procesos independentistas y de nacimiento de las repúblicas latinoamericanas provocaron una verdadera eclosión periodística. En todos los lugares, el proceso de cambio vio nacer numerosos periódicos, la mayoría de efímera existencia y Chile no fue la excepción.

Una vez consumada la independencia política, se planteó la tarea de construir la nación y encaminarla en un proyecto específico. En ello, se enfrentaron los que ponían el énfasis y la prioridad en el orden, en el supuesto que sin él ninguna nación podría progresar y los que más bien, creían que sin el desarrollo de las libertades políticas, ningún orden tendría legitimidad ni sería duradero. Posteriormente, la historiografía latinoamericana llamaría a los primeros, conservadores, y a los otros, liberales, construyendo una polaridad que, muchas veces, ocultó que, además de todo lo que los separaba y que los llevó a la confrontación, no pocas veces armada, había muchas otras cosas que los asemejaba y unía, entre ellas la adscripción discursiva a los ideales liberales y republicanos, desde la particular lectura de cada cual (Collier, 2005).

Lo que subyacía tras la pugna era el hecho de pertenecer ambos a la misma elite consolidada históricamente por la supervivencia de un modo de vida, el que se sustentaba en un particular tipo de estructura económica y social, teniendo como base a la hacienda, en tanto unidad económica, social y cultural, con clara repercusión política, al menos durante la primera mitad del siglo XIX y en la cúspide a una burguesía mercantil que había emergido en el siglo anterior (Romero, José Luis, 2001).

Dichas facciones, a pesar de sus diferencias se necesitaban de tal forma que la pugna política e ideológica, que se desata aún antes de consumada totalmente la independencia, se centra fundamentalmente en la lucha por la preponderancia del orden o la libertad política, como cimiento de la administración del sistema oligárquico. Lo anterior no significó que la contienda se circunscribiera a un campo político reglado por normas impersonales y a través de procedimientos legales establecidos. Por el contrario, y de manera similar a lo acontecido en el resto de la región, en Chile también hubo caudillismo, gobiernos y constituciones efímeras, intentos revolucionarios y represión estatal, y guerras civiles, como la que se verificó entre 1829 y 1830 que significó el triunfo del bando conservador. El orden así impuesto construyó posteriormente la imagen del país como una excepción de estabilidad política y legal.

Dicho discurso pudo asentarse en que el modelo económico colonial heredado vivió entre 1830 y 1860 el momento de su máxima expansión, lo que preparó las condiciones para la consolidación, en la segunda mitad del siglo, de un modo de producción plenamente capitalista, aunque marcado por un conjunto de particularidades que impidieron un desarrollo a la europea o norteamericana (Salazar, 2003). En ese pro- 
ceso, el ideario liberal se fue haciendo paulatinamente hegemónico, especialmente en el ámbito económico. La prensa jugó en ello un papel central. Lo anterior se expresó en el desarrollo de una tendencia predominante en lo que a los modos de hacer periodismo se refiere. La necesidad de influir en el naciente, aunque restringido espacio de debate político e ideológico, fue generando desde la propia práctica el surgimiento de un tipo especial de periódico que llegó a constituirse en una suerte de modelo, que ha sido calificado bajo el rótulo de prensa doctrinaria: "discutir fue el objetivo de la prensa del siglo XIX. Decir que esta prensa era política, de opinión o partidaria sería una redundancia. Aunque informara, esa distaba de ser su meta. La prensa irrumpió con fuerza en América Latina con los conflictos políticos e ideológicos que rodearon la Independencia y continuó siendo a lo largo del siglo, y aún entrando en el siguiente, una de los principales formas de hacer política" (Alonso, 2004: Introducción).

Lo señalado no apunta a suponer la existencia de uniformidad en las diversas expresiones de este modelo periodístico. Más aún, es posible advertir ciertos formatos diferentes, factibles de agrupar bajo la denominación de prensa doctrinaria. Por una parte, y tal vez la mayoría, producto de y concentrados en la lucha política coyuntural, instrumentos muchas veces efímeros y ocasionales de grupos y caudillos; por otro lado, periódicos cuyos contenidos y temáticas pueden ser calificados de culturales y cuyo empeño doctrinario más bien se concentraba en difundir los ideales ilustrados. Un tercer tipo es el que merece mayormente nuestra atención, y es el que dice relación con periódicos oficiales, entendiendo por tales los voceros de los gobiernos.

\section{Los orígenes del campo periodístico chileno}

El desarrollo de la prensa después de la Independencia, se caracterizó por ser generado por y dirigido a la elite oligárquica republicana. La existencia de este público restringido no solamente se explica por su control irrestricto del poder, sino que también era una cuestión por lo demás obvia en un país abrumadoramente analfabeto. Baste señalar que todavía en 1854 las personas que sabían leer y escribir alcanzaban solamente a 193.898, lo que constituía apenas el $13.5 \%$ de la población nacional (Cherniarsky, 2004).

Este naciente y restringido espacio público ilustrado hacia el que se dirigía la prensa no hacía más que reflejar lo que sucedía a nivel de la estructura política. El cuerpo de ciudadanos constituido a partir de la censitaria Constitución de 1833 era extraordinariamente pequeño. Barros Arana señala que en las elecciones parlamentarias de Marzo de 1846 votaron en total 24.347 personas y en la elección presidencial del 25 y 26 de Junio de ese mismo año, en Santiago había 6.500 inscritos, de los cuales votaron solamente 5.500, considerando que en la capital vivían unas cien mil personas. Todo ello, en un país en que la población total bordeaba el millón y medio de habitantes (Barros Arana, 2003).

En ese marco, los periódicos tenían la frágil existencia que les permitía el entusiasmo, la capacidad económica y el interés de sus promotores, activos partícipes de la lucha política intraelite y que los usaban fundamentalmente como instrumentos de coyunturas específicas y, por otra parte, tenían una circulación escasa y restringida. Cherniasky señala que, incluso en 1865, los periódicos tenían una circulación pro- 
medio de 2.904 ejemplares (Cherniarsky, 2004: 102-103). El propio El Mercurio de Valparaíso, que habría de ser el único que trascendiera su época hasta la actualidad y del que diversos autores informan que se vendía incluso en la costa del Pacífico llevado por los barcos, solamente publicaba unos mil ejemplares diarios. Al respecto, Barros Arana lo confirma: "La circulación de esos diarios no pasaba de doscientos o trescientos ejemplares, con excepción de El Mercurio, que era muy leído en toda la costa del Pacífico, pero cuyo tiraje, sin embargo, no alcanzaba seguramente a mil ejemplares" (Barros Arana, 2003: 51).

Lo anterior creaba una situación compleja para la subsistencia de la prensa, la que vino a encontrar una salida que constituye una cierta particularidad del desarrollo de la prensa nacional, con respecto a la de otros países de la región: el subsidio directo de los gobiernos, por la vía de la compra de un número de ejemplares de cada edición que se repartían en diversas reparticiones públicas. La subvención mencionada tenía una doble faz: por un lado, aparecía como un esfuerzo gubernamental para apoyar el desarrollo de la prensa y la discusión pública. Sin embargo, dicho propósito ilustrado no alcanzaba a ocultar el hecho de que generalmente era usada, más bien, como un arma para controlar a la prensa. El gobierno repartía discrecionalmente subvenciones a los periódicos que le eran afectos, “... a título de suscripción a tantos o cuantos ejemplares que eran repartidos a los senadores y diputados, y en las oficinas públicas ” (Barros Arana, 2003: 174).

El control posible de la prensa vía manejo de subsidios iba acompañado, además, de otros instrumentos al alcance de los gobiernos, en el ámbito legal. Ellos fueron los llamados Tribunales de Imprenta, ante los que podían ser acusados los periódicos y sus redactores de diversos delitos. Creados durante los años ` 20 fueron usados asiduamente por los gobiernos conservadores desde 1830 en adelante y culminaron con la dictación de la Ley de Imprenta de 1846. En el marco de restricciones descrito no es extraño que la reforma de la legislación sobre la prensa fuera una permanente bandera de los liberales y que un connotado representante, como Federico Errázuriz Zañartu -qué llegaría posteriormente a ser Presidente de la República- señalara que “...con la sanción de la ley de 1846 no se ha pretendido otra cosa que dar al gobierno un arma mortal contra la primera salvaguardia de los derechos del ciudadano, la libertad de imprenta", en su discurso de ingreso a la Facultad de Leyes y Ciencias Políticas de la Universidad de Chile, pronunciado el 14 de Agosto de 1862 (cit. Bulnes, 1950). Dicha aspiración se concretó precisamente en la administración de Errázuriz, cuando en 1872 se promulgó una nueva Ley de Imprenta que “...interpretó ampliamente los anhelos, los ideales del liberalismo, suprimiendo todo control gubernativo. Desaparecen las penas de prisión y destierro y las sanciones quedan reducidas a pequeñas multas" (Heise, 1968: 333).

En esas primeras décadas de vida republicana tenemos una prensa extraordinariamente activa y prolífica, desde el punto de vista de expresar un cierto espacio público, aunque exclusivo y excluyente, pero, a la vez, sobre bases frágiles y débiles por su subordinación a los gobiernos. Dependiente financieramente de ellos y sometida a un estricto control legal, que muchas veces excedió sus propios límites, no estuvo en condiciones de hacer emerger un campo periodístico moderno, propiamente tal. En ese 
sentido, junto al crecimiento de potenciales lectores antes mencionado, la promulgación de la Ley de Imprenta de 1872 en pleno proceso de consolidación de la hegemonía liberal, junto a otros factores económico-sociales, posibilitaron la evolución de la prensa en las últimas décadas del siglo y su paulatino cambio de carácter hacia la aparición del modelo de prensa informativa y la construcción de un mercado de prensa y un campo periodístico moderno (Ossandón y Santa Cruz, 2001).

\section{Las características de El Araucano}

Consolidado el triunfo conservador en la guerra civil que culminó en Abril de 1830, se funda El Araucano en septiembre de ese mismo año como órgano oficial del gobierno, en tanto "...periódico semanal al que se confió desde el primer instante la misión de hacer la defensa y el esclarecimiento de las medidas gubernativas" (Silva Castro, 1958: 167). Durante un par de décadas su desarrollo estuvo estrechamente ligado y su existencia subordinada a la labor intelectual y periodística de Andrés Bello.

Lo anterior provoca una suerte de paradoja. Si bien no existen muchos estudios dedicados al análisis del periódico mismo, hay una gran referencia indirecta a él, en la abundante obra que ha estudiado el pensamiento y la vida de Bello. Lo anterior da cuenta de una complejidad adicional a la hora de analizar el periódico y su presencia como actor sociocultural en la sociedad chilena de la primera mitad del siglo XIX, cual es la dificultad de separar la existencia y características del periódico de la acción y el influjo de Bello, absolutamente determinante en el desarrollo del perfil del medio. No obstante lo anterior, nueva paradoja, tampoco es posible determinar con exactitud ni las fechas de incorporación y salida de Bello de la redacción y/o dirección del periódico, ni precisar fehacientemente cuáles fueron los artículos por él redactados:

“...Para determinar la intervención de Bello en El Araucano surgen varios problemas.

Nadie discute que ella fue predominante desde la salida de Gandarillas, sin embargo, existen dudas acerca de la fecha del inicio y del cese de sus labores. No menos dificultoso resulta identificar sus artículos, ya que fueron muy variados, no realizó únicamente trabajos originales, sino también traducciones, extractos y comentarios diversos. Otra dificultad es la costumbre de los redactores de la época de no firmar los artículos y muy pocas indicar las fuentes de sus informaciones" (Hoare, 1997: 12).

Por su parte, Silva Castro, intentando precisar lo anterior, señala que “...creemos, en cambio, que la redacción de Gandarillas fue exclusiva desde la fundación del periódico hasta una fecha que no podríamos precisar. Ya en 1835 figuraba don Andrés Bello" (Silva Castro, 1958). De igual modo afirma que su labor de redacción no se prolongó más allá de 1850. Bello se habría dedicado fundamentalmente a escribir sobre los siguientes temas: la educación pública, especialmente de la organización educacional, es decir, la correlación entre los diferentes grados de la enseñanza y la mayor o menor participación del Estado; la corrección en el uso del lenguaje, especialmente en el período en que redactaba la Gramática castellana, publicada en 1847; asuntos científicos, especialmente con un sentido de divulgación; el método y el sentido de la historiografía, "...para hacer historia era necesario primero conocer bien, a fondo, con toda la precisión concedida al espíritu humano, los hechos, y no permitir jamás que las teorías vinieran a perturbar la ordenación propia de esos hechos. La pre- 
lación lógica de los sucesos ante todo, era en su entender irrenunciable" (Silva Castro, 1973: 231).

Andrea Hoare intenta una periodización específica acerca del tipo de trabajos realizado por Bello en el periódico. Así, señala que entre 1830 y 1835, "Bello se ocupa de las secciones Exterior y Variedades y editorializa con alguna frecuencia sobre temas de política internacional, de administración pública, jurídicos o institucionales, pero sin abordar los de política interna, que le corresponden a Gandarillas" (Hoare, 1997: 21); entre 1835 y 1846 habría desarrollado similares labores, pero involucrándose más en la política interna; entre 1846 y1849 disminuyeron sus trabajos directos, para, finalmente asumir la dirección entre 1850 y 1853, aunque colaborando esporádicamente.

Sin embargo, para efectos del presente texto, lo que interesa especialmente es poder determinar las características del periódico mismo y su acción sobre el espacio público y poder determinar si aquello configura un particular modelo periodístico. Otra paradoja: para nuestro propósito, la ausencia de firmas le otorga al medio la impersonalidad necesaria para hacer más visible su estructura y develar sus dispositivos discursivos. Durante el período 1830-1850, El Araucano presentó una estructura formal extraordinariamente estable, lo que ya lo distinguió del conjunto de la prensa de la época. Aparecía semanalmente, los sábados en la tarde, y constaba de cuatro páginas a tres columnas y presentó a lo largo de estas dos décadas secciones permanentes: Interior, Extranjero (Esterior), Avisos y Variedades, esta última dedicada a temas culturales y literarios. No aparece propiamente una editorial como sección específica, sino que algún artículo o comentario incluido en Interior jugaba, a veces, dicho papel.

La sección denominada Interior es tal vez la más importante, atendiendo al tipo de asuntos a que atendía. Es en ese lugar donde establece en su primera edición el programa del periódico, o si se quiere, la perspectiva a la que apunta su estrategia comunicacional. En esa dirección, señala como sus temáticas privilegiadas la administración de los negocios públicos; noticias de Europa y América; divulgación de las ciencias y las artes y su aplicación a la vida nacional; dar a conocer en el exterior la verdadera situación de Chile y dar a conocer documentos oficiales y someterlos a una crítica veraz y severa, pero sin mordacidad.

El artículo termina instalando un sentido a la labor del periódico que se cumplirá a lo largo de los años y que es central para delimitar su perfil y su carácter, al afirmar que "Los editores prometen no entrar jamás en esas controversias de partido, como algunos las califican, ni admitir comunicados sobre personalidades, sean de la clase que fueren". En esa primera edición publica otro artículo en la misma sección en que se regocija del cambio producido en la situación nacional en ese año de 1830, al enfatizar que se ha instalado un tipo de orden político situado por encima de la lucha de facciones o las ambiciones de los caudillos:

"Ya en Chile la palabra "partido" ha quedado sin significación, porque no hay individuo en todo el territorio de la República, ni fuera de él que pueda señorear las opiniones, ya los hombres no dependen de la afección de éste o aquel amigo".

La pretensión de construir un régimen político que consagrara la idea de la impersonalidad del Estado y de la administración del orden social, de clara inspiración por- 
taliana obviamente, le hace rechazar a quienes promovían la influencia política de los militares y caudillos, "como si se pretendiera que los militares son dueños de la vida de la patria, o que pueden quitársela a su salvo, porque contribuyeron a su libertad".

Posteriormente, la sección Interior es la que incorporó la publicación de decretos gubernamentales y leyes aprobadas por el Congreso, con la salvedad de que seguía todo el proceso de la tramitación de estas últimas, desde la elaboración del proyecto, consignando discusiones y opiniones acerca de sus contenidos y alcances. De este modo, el periódico va informando al público, pero también va dirigiendo esa discusión en una perspectiva política más global que apuntaba a fortalecer el orden político autoritario, sin abandonar la meta teleológica del progreso y la realización de las ideas liberales.

Además, la sección incorporaba también la publicación in extenso de las llamadas Memorias, informes anuales de su gestión presentadas por los ministros ante el Congreso, pero también por otras autoridades menores como Intendentes o comisionados para ciertas labores específicas, así como informes mensuales de ingresos y gastos de la Tesorería General de la República. Del mismo modo, incorporaba ocasionalmente reproducciones de discursos u opiniones de autoridades no gubernamentales, sino de otras instituciones como la Iglesia Católica. Así, por ejemplo, en las ediciones números 132 y 133 del 22 y 29 de Marzo de 1833, respectivamente, en que se reproduce íntegramente una Encíclica Papal o la edición del 27 de Junio de 1845 en que se reproduce el discurso de apertura de la Academia de Ciencias Sagradas, a cargo del Arzobispo Rafael Valdivieso.

Sin embargo, junto a lo anterior existía también espacio para cuestiones que resultaban menores en comparación y relacionados con la vida cotidiana. Así, por ejemplo, en el mencionado número 133 se realiza un comentario crítico al tipo de sermones del sacerdote de la Iglesia de San Pablo, que “...con frases chabacanas, anécdotas obscenas, y alusiones indecentes de que el predicador se ha valido para reprender los vicios y recomendar las virtudes".

Por su lado, la sección Exterior reproducía y/o traducía artículos provenientes de diarios de diversos países latinoamericanos y europeos, con preponderancia de temas de política interna de esas naciones o de política internacional. En ocasiones, sin embargo, se informa de otro tipo de temáticas, como ocurrió en la edición 627 del 26 de Agosto de 1842, en que se reproduce un artículo desde Venezuela acerca del descubrimiento de una gran mina de brea y la producción de asfalto, a lo que El Araucano introduce un comentario sobre los posibles usos de este nuevo producto en la industria o la construcción.

Como señalamos, la sección Variedades es la que reunía los artículos y comentarios sobre temas literarios, culturales y científicos. Es el lugar donde se ubicaron muchas de las polémicas y discusiones entabladas por Bello, así como sus preocupaciones de divulgación del conocimiento y apoyo a iniciativas ilustradas. De este modo, es posible seguir la polémica sobre la naciente historiografía nacional, a través de un comentario sobre la sesión solemne anual de la Universidad de Chile con presencia del Presidente de la República y en que la charla histórica la hizo Diego José Benavente sobre la guerra de la Independencia, antes de la Batalla de Rancagua, lo que le permitió comentar al periódico que “...El que piense hallar en el libro del Sr. Benavente el es- 
tilo imaginativo y el magisterio filosófico, de que en el día están impregnados todos los trabajos históricos con no pequeño detrimento de la verdad, verá frustradas sus esperanzas [...] ni ese prurito de alta filosofía, que corrompe la historia moderna; que saca a campaña, no ya a hombres o ejércitos, sino principios e ideas, presentándonos un drama alegórico, en que estos personajes abstractos se acechan, se buscan, se chocan, como los dioses fantásticos de la epopeya; y los historiadores intérpretes del Destino, conducen la acción en escena; en escena por rumbos misteriosos y fatales", aparecido en la edición número 789, del 3 de octubre de 1845 .

Del mismo modo, es posible mencionar dos artículos acerca de Goethe y su obra y las sensaciones dramáticas, publicados en el número 627 del 26 de Agosto de 1842, pasando por textos adjudicados a Bello con cierta certeza sobre la necesidad de adoptar el sistema métrico decimal, en los números publicados el 11 y 18 de Junio de 1847. No son pocos los artículos consagrados a la educación, no solamente en términos de sus grandes concepciones y políticas, sino que también dando cuenta, por ejemplo, elogiosamente de la publicación en Valparaíso de un texto de estudio sobre Filosofía Moderna, en el número 757 del 21 Febrero de 1845.

Finalmente, cabe destacar la existencia desde un comienzo de la sección Avisos, la que fue creciendo con el paso de los años, no solamente en espacio, sino en el tipo de cuestiones que iba incorporando. Si en su primera edición aparece la información de una tienda céntrica que ofrecía novedades en libros para la venta, durante los ` 30 se consolidan los avisos de personas que venden o arriendan propiedades urbanas o rurales o que ofrecen sus servicios, desde cirujanos a retratistas. Ya en los `40, los avisos dicen relación, además de lo anterior, con actividades comerciales. Por ejemplo, en la edición N. 757 del 21 de Febrero de 1845, se exhibe un aviso de un fabricante y vendedor de carruajes que anuncia la venta de diversos artículos relacionados importados desde Francia; cambio de dirección de una Botería y la venta de cuadernos de recetas para enfermedades, entre otros.

\section{Conclusiones}

Como apuntamos en un comienzo, desde el mismo proceso independentista surgen en América Latina y Chile periódicos oficiales, es decir, voceros de los gobiernos republicanos. Sin embargo, es posible afirmar que El Araucano encarna un modelo que establece distinciones importantes y que configura lo que podríamos denominar como modelo de prensa estatal.

En su argumentación, es preciso señalar en primer término la relación mutuamente determinante del medio con su contexto. Su existencia expresa la consolidación del predominio autoritario de una facción de la oligarquía, lograda a través de las armas y que impulsó un proyecto de orden social y político, que implicó la construcción de un tipo de Estado capaz de imponerse a la lucha intraelite. Dicho orden, consagrado en la Constitución de 1833, instaló la figura de un Presidente de la República, reelegible y dotado de amplias atribuciones, ubicado en un nivel distinto y superior a la lucha política entre grupos y personalidades. En ese plano es donde se ubicó El Araucano, portavoz no solamente del gobierno, sino que de la política del Estado, es decir, la defensa y difusión de cierta concepción del orden social y su estructura consiguiente. 
Hay ciertos factores de no menor importancia que contribuyeron a lo anterior. Por una parte, la no existencia de partidos políticos modernos, dotados de institucionalidad, directivas y programas. Más bien, se trataba de la acción de grupos o, incluso, personalidades que se articulaban en torno a coyunturas o aspiraciones más o menos inmediatas, lo que fue particularmente visible en las décadas de Prieto y, especialmente, de Bulnes. De este modo, la vida política se nucleaba, más bien, en torno a la labor de los ministros y sus relaciones con el Congreso, especialmente cuando en los años `40 el gobierno permite la presencia de algunos opositores en éste, y otros actores significativos como la Iglesia Católica, todavía iglesia oficial del Estado. No fue extraño ver el paso del oficialismo a la oposición y viceversa, motivado por discrepancias específicas o aspiraciones personales.

Todos estos grupos y personalidades, incluyendo a los propios ministros, desarrollaron una intensa actividad en el campo del periodismo. De hecho, la fundación de periódicos y revistas doctrinarias fue uno de los terrenos privilegiados para llevar a cabo su acción política. En ese sentido, El Araucano estableció una cierta distancia y en eso es posible afirmar que Bello fue decisivo. Su propósito fundamental pareció ser la conformación de un espacio público ilustrado, sostén de la acción del Estado a largo plazo y previa a, y como condición de posibilidad, de la ampliación de libertades y derechos políticos y, en ese esfuerzo, enrumbó la tarea del periódico. No resulta para nada casual que, a contar de la salida de Bello de El Araucano, a comienzos de los `50, se fuera diluyendo en su rol ideológico-cultural, sin lograr adecuarse a las transformaciones antes aludidas que comenzó a vivir el sistema político en los `60:

"En los años finales de su existencia la importancia de El Araucano en la vida intelectual de Chile fue sensiblemente menor que antes. Bello se había separado de las tareas editoriales con el objeto de consagrar todas sus horas al Código Civil, que terminó en 1856, después de más de diez años de preparación. Varios redactores tomaron a su cargo la tarea de sucederle, sin que de ninguno pudiera decirse que hizo olvidar al público la influencia que ejerció El Araucano sobre la opinión nacional en el período de Bello" (Silva Castro, 1958: 173).

Por otra parte, otro factor a considerar para explicar el lugar y el papel jugado por El Araucano en el período en estudio, es la ausencia todavía de un Otro, desde un punto de vista social primero y político después. Si bien, especialmente en lo cultural, se manifestaba la presencia de los sectores populares y plebeyos, todavía su participación en la vida política nacional se reducía, fundamentalmente, a la cooptación por parte de caudillos o de grupos afines a ideas liberales y, especialmente de sectores artesanales o populares urbanos (Grez, 1997). Es en la segunda mitad del siglo cuando la presencia del comienzo de la aglomeración popular en las ciudades y. luego, en los yacimientos mineros, instale esa preocupación en el imaginario de la oligarquía (Romero, Luis Alberto, 1997).

De modo que al analizar El Araucano nos encontramos con un periódico que operó de manera significativa sobre la sociedad de su época, especialmente en el período en que Bello le dio una impronta, pero, al mismo tiempo, fue determinado de manera decisiva por la particularidad histórica que vivió la sociedad chilena en esa etapa. Esta articulación de mutuas relaciones con su contexto le permitió un cierto grado de ori- 
ginalidad no solo nacional, sino también en la región, desarrollando un modelo periodístico sui géneris, que logró trascender de alguna manera a sus condiciones históricas.

\section{Referencias bibliográficas}

ALONSO, Paula (compiladora, 2004): Construcciones impresas. Panfletos, diarios y revistas en la formación de los estados nacionales en América Latina, 1820-1920. Buenos Aires, Fondo Cultura Económica, Introducción.

BARROS ARANA, Diego (2003): Un decenio de la historia de Chile (1841-1851). Santiago de Chile, Instituto de Historia, Pontificia Universidad Católica de Chile.

BULNES, Alfonso (1950): Errázuriz Zañartu, su vida. Santiago de Chile, Editorial Jurídica de Chile.

CHERNIARSKY, Carolina (2004): El Ferrocarril de Santiago (1855-1911). El "cuerpo" de un diario moderno, en SOTO, Angel (editor): Entre tintas y plumas. Historias de la prensa chilena del siglo XIX. Santiago de Chile, Centro de Investigaciones de Medios. Universidad de Los Andes.

COLLIER, Simón (2005): Chile, la construcción de una república. Política e ideas. 1830-1865. Santiago de Chile, Ediciones Universidad Católica de Chile.

GREZ TOSO, Sergio (1997): De la regeneración del pueblo a la huelga general. Génesis y evolución histórica del movimiento popular en Chile (1810-1890). Santiago de Chile, DIBAM-Ediciones RIL.

HEISE, Julio (1968): Historia de Chile, El periodo parlamentario (1861-1925). Santiago de Chile, Editorial Andrés Bello.

HOARE, Andrea (1997): “Andrés Bello en la historia del periodismo en Chile”. Memoria para optar al título de periodista. Universidad de Chile.

OSSANDON, Carlos y SANTA CRUZ, Eduardo (2001): Entre las alas y el plomo. La gestación de la prensa moderna en Chile. Santiago de Chile, LOM-Arcis.

ROMERO, José Luis (2001): Latinoamérica. Las ciudades y las ideas. Buenos Aires, Siglo XXI Editores Argentina.

ROMERO, Luis Alberto (1997): ¿Qué hacer con los pobres? Elite y sectores populares en Santiago de Chile. 1840-1895. Santiago de Chile, Editorial Sudamericana.

SALAZAR, Gabriel (2003): Historia de la acumulación capitalista en Chile. Santiago de Chile, LOM Ediciones.

SILVA CASTRO, Raúl (1958): Prensa y periodismo en Chile. Santiago de Chile, Ediciones Universidad de Chile.

SILVA CASTRO, Raúl (1973): “Andrés Bello en el periodismo", en VV.AA., Vida y obra de Andrés Bello. Santiago de Chile, Ediciones Universidad de Chile. 